\title{
Psychometric properties of the shortened Farsi version of the Food Cravings Questionnaire-Trait
}

Alaleh Vaziri, ${ }^{1}$ Mohammad Selehi, ${ }^{2}$ Peyman Hassani-Abharian, ${ }^{3}$ Schwan Shariatirad,${ }^{1,4}$ Alireza Mahjoub, ${ }^{1}$ Rogheye Dehjalali, ${ }^{5}$ Shadi Besarandi, ${ }^{6}$ Faraz Kasseb Danandeh ${ }^{7}$ and Alireza Noroozi ${ }^{8}$

${ }^{1}$ Students Research Centre of International Campus; ${ }^{2}$ Department of Neuroscience and Addiction Studies, School of Advanced Technologies in Medicine; 'Institute for Cognitive Sciences Studies, Tehran, Islamic Republic of Iran. ${ }^{4}$ Substance Abuse and Dependence Research Centre, University of Social Welfare and Rehabilitation Sciences, Tehran, Islamic Republic of Iran. ${ }^{5}$ Department of Psychiatry, Zanjan University of Medical Sciences, Zanjan, Islamic Republic of Iran. ${ }^{6}$ State Welfare Organization, Rasht, Islamic Republic of Iran. ${ }^{7}$ Department of Clinical Child and Adolescent Psychology, Shahid Beheshti University, Tehran, Islamic Republic of Iran. ${ }^{8}$ Iranian National Centre for Addiction Studies, Tehran University of Medical Sciences, Tehran, Islamic Republic of Iran (Correspondence to: Alireza Noroozi: a_r_noroozi@yahoo.com).

\begin{abstract}
Background: Food craving contributes to the incidence of weight and food-related disorders. Thus, an accurate measurement of food craving is important for clinical and research purposes.

Aims: We aimed to evaluate the psychometric properties of the shortened Farsi version of the Food Craving Questionnaire-Trait (FCQ-T-r), an internationally validated tool.

Methods: For this cross-sectional study, data was collected from 153 students of the University of Tehran between February and March 2019 using the Farsi version of FCQ-T-r; Depression, Anxiety and Stress Scale (DASS-21); and the Quality of Life questionnaire (WHOQOL-BREF). Confirmatory factor analysis using SPSS AMOS (version 21) failed to support the one-factor structure of FCQ-T-r in Farsi, so we conducted an exploratory factor analysis to investigate the factor structure of the questionnaire.
\end{abstract}

Results: Exploratory factor analysis reflected a 3-factor structure responsible 73.3\% of the variance factor 1 "preoccupation with food", factor 2 "lack of control over eating" and factor 3 "emotional eating". Internal consistency of the FCQ-T-r was excellent (McDonald's $\omega=0.950$ ). The FCQ-T-r scores were correlated with body mass index, DASS-21, and WHOQOL-BREF values, which supports concurrent validity of the tool.

Conclusion: The Farsi version of FCQ-T-r is a reliable and valid self-administrated tool to measure food craving traits among Iranian university students. Given the unstable factor structure of the questionnaire in different studies, further research should be conducted explore the factor structure of the tool.

Keywords: food craving, self-assessment, psychometrics, Iran , FCQ-T-r, student, university, DASS-21

Citation: Vaziri A; Selehi M; Hassani-Abharian P; Shariatirad S; Mahjoub A; Dehjalali R; et al. Psychometric properties of the reduced version of the Food Cravings Questionnaire-Trait in Farsi. East Mediterr Health J. 2022;28(1):41-49. https://doi.org/10.26719/emhj.21.066

Received: 29/01/20; accepted: 15/06/21

Copyright @ World Health Organization (WHO) 2022. Open Access. Some rights reserved. This work is available under the CC BY-NC-SA 3.0 IGO license (https://creativecommons.org/licenses/by-nc-sa/3.o/igo).

\section{Introduction}

The rising prevalence of overweight and obesity has been described as a global pandemic (1,2). In 2017, high body mass index (BMI) was estimated to cause 4.72 million deaths, and 148 million disability-adjusted life years globally (3). Obesity has now become a common health problem and its prevalence continues to increase in the developed and developing countries $(4,5)$. Socioeconomic status and demographic factors, such as education, occupation, place of residence, sex, age and marital status have been associated with excess weight $(6,7)$.

Craving is defined as an intense desire, urge or yearning to use a substance, and an important component of the current conceptualization of addictive disorders $(8,9)$. Craving could predict relapse or may negatively affect individuals' decisions for change (10). It has been added as a key symptom to the latest edition of the Diagnostic and Statistical Manual of Mental Disorders (DSM-5) (11). However, the term craving refers not only to substance use but also to impulses to do other addictive behaviours, e.g. gambling, binge-eating, shopping and gaming (12).

Food craving is characterized by a strong desire for eating a particular type of food and is associated with higher levels of weight and eating psychopathologies $(13,14)$. It could predict a lower success rate for weight-loss interventions $(15,16)$ designed to positively change eating behaviours by reducing food craving $(17,18)$. Data on food craving is important in understanding and developing interventions for weight- and eating-related disorders (8).

Several self-reported measures have been developed to assess food craving using a single question or multidimensional questionnaires (19). Some questionnaires measure craving for special kinds of foods (e.g. sweet, chocolate, savoury and rich foods) or foods in general as a trait, while others assess craving for foods as a condition $(13,20-24)$. 
The food craving questionnaire (FCQ) is one of the most usedtool in assessing cognitive, physiological, emotional and behavioural dimensions of food craving experience, both as a condition and a trait. The trait version of FCQ (FCQ-T) is a 39-item questionnaire that has nine subscales: intentions and plans to consume food, outcome expectancy of positive reinforcement, outcome expectancy of relief from negative states, anticipated lack of overeating control, preoccupation with food, physiological deficits and responses which may elicit craving, emotions experienced during food craving, external and internal cues that trigger cravings, and guilt (21).

Nine-factor structures of the FCQ-T have been replicated in several studies $(13,21,25)$, however, some studies report fewer factors $(26,27)$. The unstable factor structure and the length of the self-report questionnaire have been described as disadvantages of the FCQ-T (19). Thus, a shortened version of the FCQ-T (FCQ-T-r) was developed and validated (23).

The FCQ-T-r consists of 15 items of the German version of the FCQ-T, with the highest item-total correlations measuring craving triggered by emotional cues, intentions to consume food, and loss of control over eating. It was found to have a one-factor structure, high internal consistency, and acceptable 6-month retest reliability $(r=0.74)$ in the initial validation studies on large samples of German university students $(23,26)$. The one-factor structure of the FCQ-T-r has been replicated in some studies $(28,29)$ and it has been shown that the FCQT-r scores are associated with weight and symptoms of eating disorders in a number of studies $(22,23,28-30)$.

Given the increasing trend of obesity in the Islamic Republic of Iran $(2,31)$ and the lack of screening questionnaires for food cravings in Farsi, this study aimed to measure the psychometric properties of the Farsi version of the FCQ-T-r among Iranian university students.

\section{Methods}

\section{Participants}

This was a cross-sectional study conducted from February to March 2019 among students of technical schools at the University of Tehran.

Inclusion criteria were: being a student of the University of Tehran, male and female, and providing informed consent to participate in the study. The only exclusion criterion was unwillingness to participate in the study. Participants were 153 university students (50.3\% female) of technical majors of the University of Tehran studying at associate (5.2\%), bachelor (77.1\%), and masters or doctoral (17.6\%) levels. The response rate was high, 153 out of 160 students (95.6\%) approached agreed to participate in the study. The missing responses on the study measures were very low, ranging from $0 \%$ to $2.6 \%$. Missing values were replaced with series means.

\section{Measures}

The shortened version of Food Craving QuestionnaireTrait (FCQ-T-r) is a self-administrated questionnaire consisting of a 15 -item score using a Likert-type scale $(1=$ never, 2 = rarely, 3 = sometimes, 4 = usually, 6 = always) for possible total scores ranging from 15 to 90 . The FCQT-r is available in English language and was translated from the original German version by the questionnaire developers (23). It has shown good reliability and validity (22). The questionnaire was translated into Farsi by one member of the research team, a bilingual expert in the field of addiction research (SS). The Farsi translation was back-translated to English by another bilingual expert in addiction psychiatry (PHA). The back-translation and the English version were compared, and inconsistencies were resolved through discussions between the developer of the questionnaire (Adrian Meule), the translators and the research team.

The Farsi version of the Orientation towards Chocolate Questionnaire (32), measuring participants' attitude towards chocolate during the previous month, and the single-item visual analogue scale assessing the severity of food craving on a range from 0 to 100 were used to test the concurrent validity of FCQ-T-r in Farsi. We developed a checklist to measure craving in general for highly tempting Persian foods. The Craving for Highly Tempting Persian Foods checklist consisted of five items measuring participants' craving for eating five Persian foods: kebab with rice, a creamy sweet, Ghoemeh Sabzi stew (a traditional Persian stew with fried vegetables and meat), Fesenjan stew (a traditional Persian stew with ground walnut, pomegranate sauce and meat) and Kaleh pacheh ("head and hooves" a traditional Persian food with sheep's feet and heads, including the coveted eyes, tongue and brain). Each item was scored from 1 to 6 (1: never, 2: rarely, 3: sometimes, 4: usually, 5: mostly, 6: always). The five items were selected based on a survey among 53 students at the University of Tehran using a list of 21 common palatable Iranian foods.

We used Iranian validated versions of the Depression, Anxiety, Stress Scale (DASS-21) (33) and the World Health Organization's Quality of Life Questionnaire (WHOQOLBREF) (34) to test the concurrent validity of the Farsi version of FCQ-T-r. The DASS-21 is a set of three self-report scales designed to measure the negative emotional states of depression, anxiety and stress (35). The WHOQoLBREF is an abbreviated version of the WHOQOL-100 quality of life assessment. It is a self-administered tool with 26 questions, and it produces scores for domains related to quality of life: physical health $(\mathrm{PH}$, seven questions), psychological health (PS, six questions), social relationships (SR, three questions) and environmental health (EH, eight questions). It also includes one facet on overall quality of life and general health (36).

\section{Procedure}

Study participants were randomly selected from the list of students studying in technical schools of the University of Tehran. After giving oral consent to 
participate in the study, the students were asked to selfrate the questionnaires privately. Completion of the study assessments took about 25-30 minutes. To avoid the effect of tiredness on the part of the participants in responding to all questionnaires, we prepared study assessment packages in four different random orders. Each participant received one of four versions of study measures based on a blocked randomization list in which versions of the study assessments $(\mathrm{A}, \mathrm{B}, \mathrm{C}$ or $\mathrm{D})$ were randomly permuted in blocks of four. The first 30 participants were invited to complete FCQ-T-r after three weeks, to investigate the test-retest reliability of the Farsi version of the questionnaire. Data on height and body weight were gathered through self-report.

The study protocol and questionnaires were approved by the ethics committee of the Vice-Chancellor for Research, Tehran University of Medical Sciences (Approved ID: IR.TUMS.VCR.REC.1398.136).

\section{Data analysis}

We used SPSS, version 22, for descriptive analysis. Given that the factor structure of the FCQ-T-r has already been proposed to be unidimensional, we conducted confirmatory factor analysis using SPSS AMOS (version 21). Adequate sample size to conduct psychometric studies is subject to debate. The ratio of 10 for respondents to the questionnaire items was introduced as a rule of thumb for calculating adequate sample sizes for factor analysis studies (37). The FCQ-T-r has 15 items, so the sample size of our study $(n=153)$ was considered sufficient. Before confirmatory factor analysis, Kaiser-Meyer-Olkin analysis was conducted to measure sampling adequacy. The Kaiser-Meyer-Olkin index of sampling adequacy was 0.906 , and Barlett's test of sphericity was statistically significant indicating the suitability of data for factor analysis $\left(\chi^{2}=1862.663, P<0.001\right)$.

The single-factor structure failed to meet the recommended criteria for a good fit $\left[\chi^{2}=1949.743\right.$, $P<0.001$, non-normed fit $=0.785$, comparative fit index $=$ 0.822 , adjusted goodness of fit index $=0.858$, root mean square error of approximation $=0.157(90 \%$ confidence interval: $0.142-0.172)$, Tucker-Lewis index $=0.785$, Akaike information criterion $=6841.235]$. Therefore, we conducted an exploratory factor analysis to investigate the factor structure of the questionnaire. To check the suitability of data for factor analysis, we used the KaiserMeyer-Olkin measure of sampling adequacy and Barlett's test of sphericity. Given the problems with Cronbach's $\alpha$ to assess the internal reliability of the questionnaire (38), we reported McDonald's $\omega$ using JASP software (version o.11.1) in addition to Cronbach's $\alpha$. McDonald's $\omega$ provides a more accurate approximation of internal consistency for scales with heterogeneous items (39).

We used Pearson correlations between scores at the first and second measurements for the FCQ-T-r to measure test-retest reliability. Pearson's correlation was used to explore the association between FCQ-T-r and scores on the Orientation towards Chocolate Questionnaire, the
Craving for Highly Tempting Persian Foods checklist, DASS-21, WHOQOL-BREF, visual analogue scale, BMI and weight dissatisfaction.

\begin{tabular}{|c|c|c|}
\hline Characteristic & No. & $\%$ \\
\hline \multicolumn{3}{|l|}{ Sex } \\
\hline Female & 77 & 50.3 \\
\hline Male & 76 & 49.7 \\
\hline \multicolumn{3}{|l|}{ Marital status } \\
\hline Single & 138 & 90.2 \\
\hline Married & 15 & 9.8 \\
\hline \multicolumn{3}{|l|}{ No. of children } \\
\hline 0 & 148 & 96.7 \\
\hline 1 & 4 & 2.6 \\
\hline 2 & 0 & 0.0 \\
\hline 3 & 1 & 0.7 \\
\hline \multicolumn{3}{|l|}{ No of pregnancies, female participants $(n=77)$} \\
\hline 0 & 73 & 94.8 \\
\hline 1 & 3 & 3.9 \\
\hline 2 & 0 & 0.0 \\
\hline 3 & 1 & 1.3 \\
\hline \multicolumn{3}{|l|}{ Employment } \\
\hline Unemployed & 145 & 94.8 \\
\hline Employed & 8 & 5.2 \\
\hline \multicolumn{3}{|l|}{ Satisfaction with body weight } \\
\hline Yes & 92 & 60.1 \\
\hline No & 61 & 39.9 \\
\hline \multicolumn{3}{|l|}{ Satisfaction with body shape } \\
\hline Yes & 105 & 68.6 \\
\hline No & 48 & 31.4 \\
\hline \multicolumn{3}{|l|}{ History of dieting } \\
\hline Yes & 35 & 22.8 \\
\hline \multirow[t]{2}{*}{ No } & 118 & 77.2 \\
\hline & Mean & SD \\
\hline Age & 22.07 & 3.18 \\
\hline Height $(\mathrm{cm})$ & 172.30 & 9.24 \\
\hline Body weight (kg) & 67.76 & 14.16 \\
\hline Body mass index $\left(\mathrm{kg} / \mathrm{m}^{2}\right)$ & 22.85 & 3.82 \\
\hline No. of people in family (including participant) & 4.52 & 1.45 \\
\hline $\begin{array}{l}\text { No. of times participants eat in fast-food restaurants/ } \\
\text { month }\end{array}$ & 2.48 & 2.70 \\
\hline $\begin{array}{l}\text { No. of times participants eat in restaurants other than } \\
\text { fast-foods/month }\end{array}$ & 1.80 & 3.29 \\
\hline Total no. of times participants eat in restaurants/month & 3.79 & 4.18 \\
\hline $\begin{array}{l}\text { No. of times participants go to the cinema, theatre or } \\
\text { museum/month }\end{array}$ & 1.16 & 2.01 \\
\hline No. of successful dieting attempts & 1.76 & 0.44 \\
\hline No. of failed dieting attempts & 0.69 & 2.33 \\
\hline Longest period of dieting (months) & 0.84 & 2.59 \\
\hline Greatest weight loss achieved with dieting $(\mathrm{kg})$ & 1.67 & 4.38 \\
\hline
\end{tabular}




\begin{tabular}{|c|c|c|c|c|c|c|}
\hline \multirow[t]{3}{*}{ Component } & \multicolumn{6}{|c|}{ Sum of squared loadings } \\
\hline & \multicolumn{3}{|c|}{ Extraction } & \multicolumn{3}{|c|}{ Rotation } \\
\hline & Total & $\%$ of variance & Cumulative \% & Total & $\%$ of variance & Cumulative \% \\
\hline 1 & 8.851 & 59.005 & 59.005 & 4.386 & 29.242 & 29.242 \\
\hline 2 & 1.092 & 7.282 & 66.288 & 3.517 & 23.448 & 52.690 \\
\hline 3 & 1.052 & 7.013 & 73.300 & 3.091 & 20.610 & 73.300 \\
\hline
\end{tabular}

Component 1: "thoughts or preoccupation with food" consisted of 6 items that explained $29.2 \%$ of the variance referred.

Component 2: "lack of control over eating" consisted of 6 items that explained $23.4 \%$ of the variance.

Component 3: "emotional eating" consisted of 3 items and explained $20.6 \%$ of the variance.

\section{Results}

The mean [standard deviation (SD)] age of participants was 22.07 (SD 3.18), in a range from 18 to 37 years. A history of diet for weight loss was reported by $22.8 \%$ of participants. The female:male ratio was almost equal (50.3\% female and $49.7 \%$ male). The FCQ-T-r scores were not significantly different between female (38.38, SD 18.52) and male (37.58, SD 18.52) participants. The mean BMI of participants was 22.85 (SD 3.82; range 17.80-41.50) kg/ $\mathrm{m}^{2}$. Other demographic characteristics and weight- and diet-related data are presented in Table 1.

The range of the factor loadings for the items, their variances and eigenvalues are presented in Table 2 . Three components had eigenvalues greater than 1.00 and these represent $73.3 \%$ of the variance. The first factor represents a high proportion of the variance $(29.2 \%)$ and comprised six items. This factor was referred to as "thoughts or preoccupation with food". The second factor represents $23.4 \%$ of the variance and comprised six items asking questions regarding "lack of control over eating". The third factor comprised three items and represents $20.6 \%$ of the variance measuring "emotional eating". The results of factor analysis with a varimax rotation for the items in the FCQ-T-r are shown in Table 3. The rotated component matrix helps determine what the components represent. It contains estimates of the correlations between each of the variables and the estimated components.

Internal reliability of the FCQ-T-r was excellent with both McDonald's $\omega$ (0.950) and Cronbach's $\alpha$ (0.949) statistics. Means for FCQ-T-r items, McDonald's $\omega$ and Cronbach's $\alpha$ for the questionnaire for the item deleted and total-item correlations are presented in Table 4. Totalitem correlations were all statistically significant $(P<$ o.01). The FCQ-T-r scores at the second measurement had a significant, strong positive correlation with the firsttime measurement $(r=0.82, P<0.001)$, which indicates a high three-week retest reliability for the questionnaire.

Table 3 Rotated component matrix for items on the shortened version (in Farsi) of the Food Craving Questionnaire-Trait (FCQT-r), Tehran, 2019

\begin{tabular}{|c|c|c|c|}
\hline \multirow[t]{2}{*}{ Item } & \multicolumn{3}{|c|}{$\begin{array}{c}\text { Estimate of correlation } \\
\text { Component }\end{array}$} \\
\hline & 1 & 2 & 3 \\
\hline 1. When I crave something, I know I won't be able to stop eating once I start. & & 0.804 & \\
\hline 2. If I eat what I am craving, I often lose control and eat too much. & & 0.814 & \\
\hline 3. Food cravings invariably make me think of ways to get what I want to eat. & 0.706 & & \\
\hline 4. I feel like I have food on my mind all the time. & 0.798 & & \\
\hline 5. I find myself preoccupied with food. & 0.735 & & \\
\hline 6. Whenever I have cravings, I find myself making plans to eat. & 0.782 & & \\
\hline 7. I crave foods when I feel bored, angry, or sad. & & & 0.593 \\
\hline 8. I have no willpower to resist my food craving. & & 0.624 & \\
\hline 9. Once I start eating, I have trouble stopping. & & 0.563 & \\
\hline 10. I can't stop thinking about eating no matter how hard I try. & & 0.578 & \\
\hline 11. If I give in to a food craving all control is lost. & & 0.797 & \\
\hline 12. Whenever I have a food craving, I keep on thinking about eating until I actually eat the food. & 0.721 & & \\
\hline 13. If I am craving something, thoughts of eating it consume me. & 0.747 & & \\
\hline 14. My emotions often make me want to eat. & & & 0.671 \\
\hline 15. It is hard for me to resist the temptation to eat appetizing foods that are in my reach. & & & 0.600 \\
\hline
\end{tabular}

Component 1: "thoughts or preoccupation with food" consisted of 6 items that explained $29.2 \%$ of the variance referred.

Component 2: "lack of control over eating" consisted of 6 items that explained $23.4 \%$ of the variance.

Component 3: "emotional eating" consisted of 3 items and explained $20.6 \%$ of the variance. 
Table 4 Correlation statistics for items on the shortened version of the Food Craving Questionnaire-Trait (FCQ-T-r) in Farsi ( $n=$ 153), Tehran, 2019

\begin{tabular}{|c|c|c|c|c|c|}
\hline Item & Mean (SD) & $\omega$ & $\begin{array}{l}\text { Item } \\
\text { loading }\end{array}$ & $\alpha$ & $\begin{array}{l}\text { Total } \\
\text { correlation }\end{array}$ \\
\hline 1. When I crave something, I know I won't be able to stop eating once I start. & $2.95(1.56)$ & 0.947 & 0.798 & 0.848 & $0.737^{*}$ \\
\hline 2. If I eat what I am craving, I often lose control and eat too much. & $2.96(1.46)$ & 0.948 & 0.773 & 0.846 & $0.844^{*}$ \\
\hline 3. Food cravings invariably make me think of ways to get what I want to eat. & $3.32(1.44)$ & 0.948 & 0.700 & 0.916 & $0.703^{*}$ \\
\hline 4. I feel like I have food on my mind all the time. & $2.66(1.52)$ & 0.945 & 0.801 & 0.895 & $0.859^{*}$ \\
\hline 5. I find myself preoccupied with food. & $2.56(1.55)$ & 0.946 & 0.737 & 0.903 & $0.800^{*}$ \\
\hline 6. Whenever I have cravings, I find myself making plans to eat. & $2.77(1.47)$ & 0.947 & 0.706 & 0.911 & $0.743^{*}$ \\
\hline 7. I crave foods when I feel bored, angry, or sad. & $2.41(1.50)$ & 0.951 & 0.553 & 0.904 & $0.507^{*}$ \\
\hline 8. I have no willpower to resist my food craving. & $2.24(1.42)$ & 0.945 & 0.722 & 0.911 & $0.737^{*}$ \\
\hline 9. Once I start eating, I have trouble stopping. & $2.51(1.48)$ & 0.946 & 0.691 & 0.869 & $0.722^{*}$ \\
\hline 10. I can't stop thinking about eating no matter how hard I try. & $2.03(1.42)$ & 0.945 & 0.769 & 0.860 & $0.783^{*}$ \\
\hline 11. If I give in to a food craving all control is lost. & $1.93(1.30)$ & 0.945 & 0.836 & 0.852 & $0.844^{*}$ \\
\hline $\begin{array}{l}\text { 12. Whenever I have a food craving, I keep on thinking about eating until I } \\
\text { actually eat the food. }\end{array}$ & $2.46(1.53)$ & 0.945 & 0.785 & 0.903 & $0.802^{*}$ \\
\hline 13. If I am craving something, thoughts of eating it consume me. & $1.93(1.53)$ & 0.949 & 0.710 & 0.879 & $0.664^{*}$ \\
\hline 14. My emotions often make me want to eat. & $2.33(1.43)$ & 0.946 & 0.737 & 0.862 & $0.770^{*}$ \\
\hline $\begin{array}{l}\text { 15. It is hard for me to resist the temptation to eat appetizing foods that are in my } \\
\text { reach. }\end{array}$ & $2.91(1.55)$ & 0.947 & 0.676 & 0.844 & $0.784^{*}$ \\
\hline
\end{tabular}

A statistically significant, positive correlation was found between FCQ-T-r scores and body weight ( $r=$ $0.23, P=0.008)$, BMI $(r=0.14 P=0.002)$ and age $(r=0.28$, $P=0.001)$. The FCQ-T-r scores indicated significant, strong, positive correlation with severity of food craving measured by a visual analogue scale $(r=0.66, P<0.001)$, the Craving for Highly Tempting Persian Foods checklist $(r=0.62, P<0.001)$ and the Orientation towards Chocolate questionnaire $(r=0.59, P<0.001)$. The FCQ-T-r scores had a significantly moderate and positive correlation with DASS-21 scores $(r=0.38, P<0.001)$, and showed a significant weak correlation with anxiety sub-scales scores $(r=0.27, P=0.001)$. However, a significant, positive and moderate correlation was found between FCQT-r scores and depression $(r=0.32, P<0.001)$ and stress $(r=0.42, P<0.001)$. The FCQ-T-r scores showed a significantly and negatively weak correlation with WHOQOL-BREF scores $(r=-0.23, P=0.004)$.

The FCQ-T-r scores were positively correlated with number of failed dieting attempts $(r=0.23, P=0.007)$ and total number of dieting attempts $(r=0.15, P=0.05)$. The correlation between the reported number of successful dieting attempts and FCQ-T-r was not significant ( $r=$ $-0.10, P=0.229$ ).

\section{Discussion}

In this study, we measured the psychometric properties of the FCQ-T-r (15-items) in Farsi. The FCQ-T-r is a short form of the FCQ-T questionnaire (39-items) which was previously validated in different languages (19). The full version of the FCQ-T has previously been validated in Farsi (40). The items on the FCQ-T-r ask about cravings for eating and foods in general, which could be the strength of this questionnaire over other questionnaires that have focused on a specific kind of food.

The confirmatory factor analysis did not support a single factor structure, which is consistent with the results of a study reporting psychometric properties of FCQ-T-r in the English language (22). In this study, confirmatory factor analysis showed poor fit with onefactor structure, however, parallel analyses and visual inspection of the scree plot for the principal component analysis supported a single-factor model. A study among overweight and obese Iranian women in the Islamic Republic of Iran reported that a three-factor structure for FCQ-T-r cumulatively represents $63.14 \%$ of the variance (41). Our results were not consistent with studies in original German (23), Italian (28-29), Portuguese (42), Spanish (43) and French (44) versions of the questionnaire, which supported a single factor structure. The unstable factor structure of FCQ-T-r in different studies warrants further research to determine the factor structure of the Farsi FCQ-T-r among general and clinical populations.

Our results show that the Farsi version of FCQ-T-r had excellent internal consistency, which is consistent with the high internal reliability reported in the FCQ-T-r in German (23) and other languages (22,29,42-44). The FCQT-r scores had a high three-week retest reliability. This is in line with the finding of high half-year retest reliability $(r=0.74)$ in the initial validation study assessing food cravings in a large sample of German university students (45). 
Significant positive correlations of FCQ-T-r scores with body weight, BMI, and food craving questionnaires, DASS-21 and WHOQOL-BREF, support the concurrent validity of the questionnaire. However, the correlations with BMI and body weight were weak. These findings were consistent with international studies reporting significant correlations between FCQ-T-r scores and negative effect and distorted eating $(23,28,43,44)$.

To better understand the nature of food addiction, further research on correlations of food craving with weight-related disorders and psychiatric disorders, including, eating, mood, impulse control and substancerelated and addictive disorders are suggested.

Our study had some limitations, including small sample size and recruiting young participants with low variability in weight and BMI, which limited the generalizability of our results to the broad population. To increase the generalizability of findings, further studies are needed on larger and more representative samples in terms of age and BMI.

\section{Conclusion}

We found that the Farsi version of the FCQ-T-r is a valid and reliable tool to measure trait food craving among university students in the Islamic Republic of Iran. It is an easy-to-use, brief, self-administrated questionnaire that seems to be a viable instrument for investigating food cravings, particularly in time-constrained settings. Further studies are needed to investigate its suitability to use in more diverse populations and clinical samples.

\section{Acknowledgement}

The authors would like to warmly thank Adrian Meule, the study participants and the staff of the University of Tehran for their kind collaboration. We would also like to acknowledge the staff of the Students Research Centre of International Campus and Vice-Chancellor for Research, Tehran University of Medical Sciences for their support.

Funding: Students Research Centre of International Campus, Tehran University of Medical Sciences.

Competing interests: None declared.

\section{Propriétés psychométriques de la version courte en langue perse du questionnaire sur les traits compulsifs alimentaires}

\section{Résumé}

Contexte : Il a été démontré que les compulsions alimentaires contribuent à la prise de poids et aux pathologies liées à l'alimentation. Ainsi, une mesure précise de ces compulsions est importante à des fins cliniques et de recherche.

Objectifs : Notre objectif était d'évaluer les propriétés psychométriques de la version courte en langue perse du questionnaire sur les traits compulsifs alimentaires (FCQ-T-r), un outil validé à l'échelle internationale.

Méthodes : Pour la présente étude transversale, 153 étudiants de l'Université de Téhéran ont été recrutés entre février et mars 2019. Les mesures de l'étude comprenaient la version en langue perse du questionnaire sur les traits compulsifs du FCQ-T-r, l'échelle de dépression, d'anxiété et de stress (DASS-21) et le questionnaire sur la qualité de vie (WHOQOL-BREF). L'analyse factorielle confirmatoire utilisant le logiciel SPSS AMOS (version 21) n'ayant pas réussi à soutenir la structure factorielle unique du questionnaire sur les traits compulsifs alimentaires en langue perse, nous avons donc effectué une analyse factorielle exploratoire pour examiner la structure factorielle du questionnaire.

Résultats : L'analyse factorielle exploratoire a mis en évidence une structure à trois facteurs : le facteur 1 « préoccupation alimentaire », le facteur 2 « manque de contrôle sur l'alimentation » et le facteur 3 《l'alimentation émotionnelle » expliquant $73,3 \%$ de la variance. La cohérence interne du questionnaire sur les traits compulsifs alimentaires était excellente (McDonald $\omega=0,950)$. Les scores du questionnaire sur les traits compulsifs alimentaires étaient corrélés aux valeurs de l'indice de masse corporelle, du DASS-21 et du questionnaire sur la qualité de vie (WHOQOL-BREF), ce qui confirme la validité simultanée de l'outil.

Conclusion : Le questionnaire sur les traits compulsifs alimentaires (en langue perse) est un outil auto-administré fiable et valide visant à mesurer lesdites traits chez les étudiants universitaires iraniens. Étant donné la structure factorielle instable du questionnaire dans différentes études, d'autres recherches visant à explorer cette structure sont nécessaires. 


\section{خصائص القياسِ النَّفْي للنسخة الموجزة من استبيان سلات الرغبة الشديدة في تناول الطعام باللغة الفارسية}

علال وزيري، محمد صالحي، بيمان حساني-أبهاريان، شوان شارياتيراد، علي رضا محجوب، روجيه دجلالي، شادي بيساراندي، فاراز دانانديه، علي رضانوروزي

الخلاصة

الخلفية: تبين أنً الرغبة الشديدة في تناول الطعام تسهم في زيادة الوزن والأمراض المرتبطة بالأغذية. لذا، يعد القياس الدقيق للرغبة الشديدة في

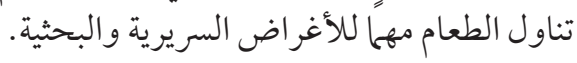

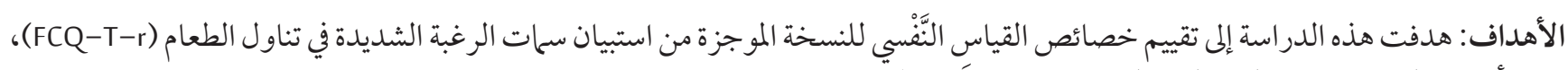
وهي أداة تم التحقق منها دوليًا، باللغة الفارسية.

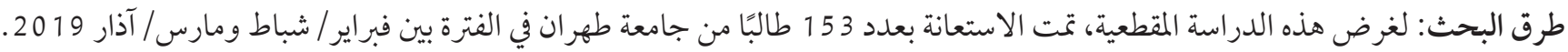

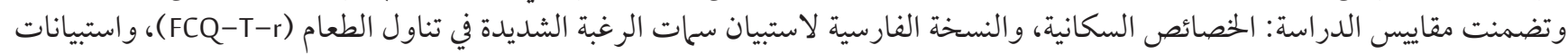

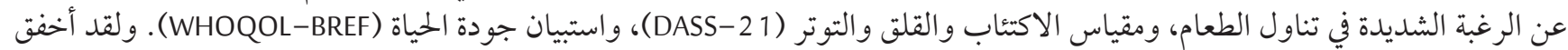

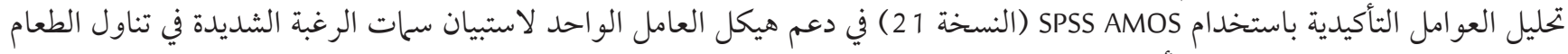
(FCQ-T-r)

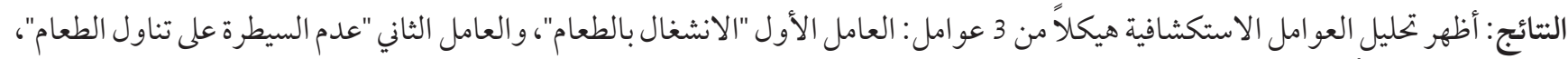

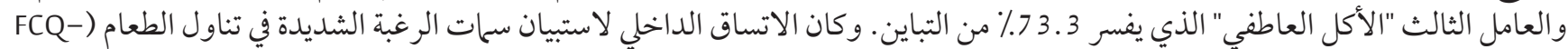

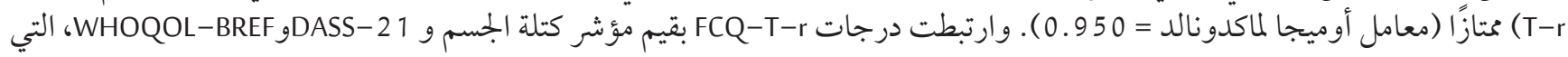
تدعم الصلاحية المتز امنة للأداة.

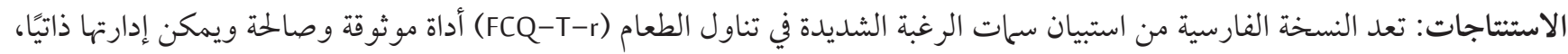

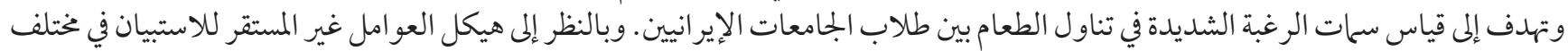

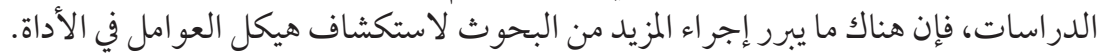

\section{References}

1. Jaacks LM, Vandevijvere S, Pan A, McGowan CJ, Wallace C, Imamura F, et al. The obesity transition: stages of the global epidemic. Lancet Diabetes Endocrinol. 2019;7(3):231-40. doi:10.1016/S2213-8587(19)30026-9

2. NCD Risk Factor Collaboration (NCD-RisC). Worldwide trends in body-mass index, underweight, overweight, and obesity from 1975 to 2016: a pooled analysis of 2416 population-based measurement studies in $128 \cdot 9$ million children, adolescents, and adults. Lancet. 2017;390(10113):2627-42. doi:10.1016/S0140-6736(17)32129-3

3. GBD 2017 Risk Factor Collaborators. Global, regional, and national comparative risk assessment of 84 behavioral, environmental and occupational, and metabolic risks or clusters of risks for 195 countries and territories, 1990-2017: a systematic analysis for the Global Burden of Disease Study 2017. Lancet. 2018;392(10159):1923-94. doi:10.1016/So140-6736(18)32225-6

4. Popkin BM, Adair LS, Ng SW. Global nutrition transition and the pandemic of obesity in developing countries. Nutr Rev. 2012;70(1):3-21. doi:10.1111/j.1753-4887.2011.00456.x

5. Stevens GA, Singh GM, Lu Y, Danaei G, Lin JK, Finucane MM, et al. Global Burden of Metabolic Risk Factors of Chronic Diseases Collaborating Group (Body Mass Index). National, regional, and global trends in adult overweight and obesity prevalence. Popul Health Metr. 2012;10(1):22. doi:10.1186/1478-7954-10-22

6. Swinburn BA, Sacks G, Hall KD, McPherson K, Finegood DT, Moodie ML, et al. The global obesity pandemic: shaped by global drivers and local environments. Lancet. 2011;378(9793):804-14. doi:10.1016/So140-6736(11)60813-1

7. NCD Risk Factor Collaboration (NCD-RisC). Rising rural body-mass index is the main driver of the global obesity epidemic in adults. Nature. 2019;569(7755):260-4. doi:10.1038/s41586-019-1171-x

8. Potenza MN, Grilo CM. How relevant is food craving to obesity and its treatment? Front Psychiatry. 2014;5:164. doi:10.3389/fpsyt.2014.00164

9. Sayette MA. The Role of Craving in Substance Use Disorders: Theoretical and Methodological Issues. Annu Rev Clin Psychol. 2016;12:407-33. doi:10.1146/annurev-clinpsy-021815-093351

10. Tiffany ST, Wray JM. The clinical significance of drug craving. Ann N Y Acad Sci. 2012;1248:1-17. doi:10.1111/j.17496632.2011.06298.x

11. American Psychiatric Association. Diagnostic and statistical manual of mental disorders. Arlington, VA: American Psychiatric Publishing, 2013.

12. Koob GF. Impulse control disorders. San Diego: Cognella, 2013. 
13. Cepeda-Benito A, Fernández MC, Moreno S. Relationship of gender and eating disorder symptoms to reported cravings for food: Construct validation of state and trait craving questionnaires in Spanish. Appetite. 2003;40(1):47-54. doi:10.1016/So1956663(02)00145-9

14. Chao A, Grilo CM, White MA, Sinha R. Food cravings, food intake, and weight status in a community-based sample. Eat Behav. 2014;15(3):478-82. doi:10.1016/j.eatbeh.2014.06.003

15. Buscemi J, Rybak TM, Berlin KS, Murphy JG, Raynor HA. Impact of food craving and calorie intake on body mass index (BMI) changes during an 18-month behavioral weight loss trial. J Behav Med. 2017;40(4):565-73. doi:10.1007/s10865-017-9824-4

16. Dalton M, Finlayson G, Walsh B, Halseth AE, Duarte C, Blundell JE. Early improvement in food cravings are associated with long-term weight loss success in a large clinical sample. Int J Obes (Lond). 2017;41(8):1232-6. doi:10.1038/ijo.2017.89

17. Alberts HJ, Thewissen R, Raes L. Dealing with problematic eating behaviour. The effects of a mindfulness-based intervention on eating behaviour, food cravings, dichotomous thinking and body image concern. Appetite. 2012;58(3):847-51. doi:10.1016/j. appet.2012.01.009

18. Rebello CJ, Nikonova EV, Zhou S, Aronne LJ, Fujioka K, Garvey WT, Smith SR, Coulter AA, Greenway FL. Effect of Lorcaserin Alone and in Combination with Phentermine on Food Cravings after 12-Week Treatment: A Randomized Substudy. Obesity (Silver Spring). 2018;26(2):332-339. doi:10.1002/oby.22094

19. Taylor M. A review of food craving measures. Eat Behav. 2019;32:101-10. doi:10.1016/j.eatbeh.2019.01.005

20. Cartwright F, Stritzke WG. A multi-dimensional ambivalence model of chocolate craving: construct validity and associations with chocolate consumption and disordered eating. Eat Behav. 2008;9(1):1-12. doi:10.1016/j.eatbeh.2007.01.006

21. Cepeda-Benito A, Gleaves DH, Williams TL, Erath SA. The development and validation of the state and trait Food-Cravings Questionnaires. Behav Ther. 2000;31(1):151-73. doi:10.1016/So005-7894(00) 80009-X

22. Hormes JM, Meule A. Psychometric properties of the English Food Cravings Questionnaire-Trait-reduced (FCQ-T-r). Eat Behav. 2016;20:34-8. doi:10.1016/j.eatbeh.2015.11.011

23. Meule A, Hermann T, Kübler A. A short version of the Food Cravings Questionnaire-Trait: the FCQ-T-reduced. Front Psychol. 2014;5:190. doi:10.3389/fpsyg.2014.00190

24. Van Gucht D, Soetens B, Raes F, Griffith JW. The Attitudes to Chocolate Questionnaire. Psychometric properties and relationship with consumption, dieting, disinhibition and thought suppression. Appetite. 2014;76:137-43. doi:10.1016/j.appet.2014.01.078

25. Innamorati M, Imperatori C, Balsamo M, Tamburello S, Belvederi Murri M, Contardi A, et al. Food Cravings Questionnaire-Trait (FCQ-T) discriminates between obese and overweight patients with and without binge eating tendencies: the Italian version of the FCQ-T. J Pers Assess. 2014;96(6):632-9. doi:10.1080/00223891.2014.909449

26. Meule A, Lutz A, Vögele C, Kübler A. Food cravings discriminate differentially between successful and unsuccessful dieters and non-dieters. Validation of the food craving questionnaires in German. Appetite. 2012;58(1):88-97. doi:10.1016/j.appet.2011.09.010

27. Crowley N, Madan A, Wedin S, Correll JA, Delustro LM, et al. Food cravings among bariatric surgery candidates. Eat Weight Disord. 2014;19(3):371-6. doi:10.1007/s40519-013-0095-y

28. Iani L, Barbaranelli C, Lombardo C. Cross-validation of the reduced form of the food craving questionnaire-trait using confirmatory factor analysis. Front Psychol. 2015;6:433. doi:10.3389/fpsyg.2015.00433

29. Innamorati M, Imperatori C, Meule A, Lamis DA, Contardi A, Balsamo M, et al. Psychometric properties of the Italian food cravings questionnaire-trait-reduced (FCQ-T-r). Eat Weight Disord. 2015 20(1):129-35. doi:org/10.1007/s40519-014-0143-2

30. Rodriguez-Martin BC, Molerio-Perez O. Exploring the factor structure of the food cravings questionnaire-trait in Cuban adults. Front Psychol. 2014;5:214. doi:10.3389/fpsyg.2014.00214

31. Rahmani A, Sayehmiri K, Asadollahi K, Sarokhani D, Islami F, Sarokhani M. Investigation of the Prevalence of Obesity in Iran: A Systematic Review and Meta-Analysis Study. Acta Med Iran. 2015;53(10):596-607. PMID:26615371

32. Fadavi Roodsari A, Khalatbari J. Psychometric Evaluation of the Persian Version of the Orientation towards Chocolate Questionnaire. J Soc Iss Hum. 2014;2(5): 290-7.

33. Asghari A, Saed F, Dibajnia P. Psychometric properties of the Depression Anxiety Stress Scales-21 (DASS-21) in a non-clinical Iranian sample. Int J Psychol. 2008;2(2):82-102.

34. Yousefy AR, Ghassemi GR, Sarrafzadegan N, Mallik S, Baghaei AM, Rabiei K. Psychometric properties of the WHOQOL-BREF in an Iranian adult sample. Community Ment Health J. 2010;46(2):139-47. doi:10.1007/s10597-009-9282-8

35. Lovibond PF, Lovibond SH. The structure of negative emotional states: comparison of the Depression Anxiety Stress Scales (DASS) with the Beck Depression and Anxiety Inventories. Behav Res Ther. 1995;33(3):335-43. doi:10.1016/0005-7967(94)0oo75-u

36. World Health Organization. Development of the World Health Organization WHOQOL-BREF quality of life assessment. The WHOQOL Group. Psychol Med. 1998;28(3):551-8. doi:10.1017/s0033291798006667

37. Terwee CB, Bot SD, de Boer MR, van der Windt DA, Knol DL, Dekker J, et al. Quality criteria were proposed for measurement properties of health status questionnaires. J Clin Epidemiol. 2007 Jan;60(1):34-42. doi:10.1016/j.jclinepi.2006.03.012

38. Peters GJY. The alpha and the omega of scale reliability and validity: why and how to abandon Cronbach's alpha and the route towards more comprehensive assessment of scale quality. Eur Health Psychol. 2014;16(2):56-69. doi:10.31234/osf.io/h47fv

39. Revelle W, \& Zinbarg RE. Coefficients Alpha, Beta, Omega, and the glb: comments on Sijtsma. Psychometrika, 2009;74(1), 145-54. doi:10.1007/s11336-008-9102-Z 
40. Kachooei M, Ashrafi E. Exploring the factor structure, reliability and validity of the food craving questionnaire-trait in Iranian adults. J Kerman Uni Med Sci. 2016;23(5), 631-48.

41. Mohammadi MR, Akhondzadeh S, Mostafavi SA, Keshavarz SA, Ahmadi Motlaq T, Eshraghian MR, et al. The reliability and validity of the Persian version of Food Craving Questionnaire-Trait-Reduced (FCQ-T-r) in Overweight and Obese Women. J Nutr Fasting Health. 2018;6(3):150-7. doi:10.22038/JNFH.2018.35221.1150

42. Queiroz de Medeiros AC, Pedrosa LDFC, Yamamoto ME. Exploring the structural and construct validity of the Brazilian Food Cravings Questionnaire-Trait-reduced (FCQ-T-r). Br J Psychiatry. 2019;41:66-9. doi:10.1590/1516-4446-2017-0019

43. Rodríguez-Martín B,Molerio-Pérez O. Exploring the factor structure of the Food Cravings Questionnaire-Trait in Cuban adults. Front Psychol. 2014;5(214):1-12. doi:org/10.3389/fpsyg.2014.00214

44. Brunault P, El Archi S, Ballon N, Réveillère C, Barrault S. Validation of the French version of the Food Cravings Questionnaire-Trait-Reduced: an easy-to-use and quick self administered questionnaire to assess food craving. Ann Med Psychol. 2018;176:788-95. doi:10.1016/j.amp.2018.08.002

45. Meule A, Teran CB, Berker J, Gründel T, Mayerhofer M, Platte P. On the differentiation between trait and state food craving: half-year retest-reliability of the Food Cravings Questionnaire-Trait-reduced (FCQ-T-r) and the Food Cravings Questionnaire-State (FCQ-S). J Eat Disord. 2014;2(1):25. doi:10.1186/s40337-014-0025-Z 